international allocation of such wave-lengths for short-wave broadcasting after the War must therefore be based on the ionospheric results obtained. during the last sunspot cycle.

\section{The Logic of Question and Answer}

In the issue of Mind for January 1943, Prof. A. D. Ritchie, under the title "The Logic of Question and Answer", discusses problems connected with the use of hypotheses in scientific method. He begins by denying the existence of 'hard' facts, a denial which should be platitudinous now but is not. A single observation, he argues, does not by itself provide empirical information. This is the function of a plurality of observations in certain relations. $\mathrm{He}$ goes on to develop the contention (which he derives from Prof. Collingwood's philosophy) that every proposition which really contributes to knowledge is an answer to a question, and that the question arises out of pre-existing knowledge, this knowledge itself being the answer to a previous question or questions. The fundamental question is always "What have we here ?" If we ask the question about, say, a truck-load of coal, we find the answer by inspecting and testing samples. The number of samples we take and the way in which we take them will depend on knowledge we already possess about the coal, the method in which it is loaded in the truck, whether it is protected from the elements, etc. If we ask how we know that the samples are representative of the material, the answer is that we have chosen a way of sampling which answers the questions we were asking. If our questions are not answered, we must devise another method of sampling.

If all questions depend, in the way stated, on answers to previous questions, we must, it seems, at some point come back to absolute presuppositions. Prof. Collingwood drew this conclusion and further argued that each historical epoch had its own absolute presuppositions. Prof. Ritchie argues, first, that as we trace our questions and answers back we come to a point where what we have is some vague knowledge which is thrown at us by experience with a minimum of questioning and presupposition; secondly, that the presuppositions underlying the process of scientific discovery are purely formal, consist in something like Kant's list of categories, and must be common to all historical epochs because the process of scientific discovery is continuous.

\section{Health Services in Great Britain}

The February issue of Agenda is noteworthy for an article by Prof. Henry Cohen, "A Comprehensive Health Service". Surveying the various reports on the health services which have followed the P E P report of December 1937, Prof. Cohen stresses the point that medical opinion should be considered expert only in relation to the organization and administration of health services. Questions relating to the various methods of raising the necessary finance are outside its special province. Next, he urges that any plan for the future health service of Great Britain must not overlook the vital factors of provision for the training of personnel (medical education) and of encouraging the advancement of medical knowledge (research). In regard to personnel, Prof. Cohen emphasizes the importance of the general practitioner, who should know not only the patient's body but also his job, his home, his relations. Neither patient nor practitioner should be forced unwillingly into a professional relationship. In addition to this personal relation of medical man and patient, and the maximum freedom of choice, every citizen should have the right to adequate and, so far as possible, the best available provision for the prevention and cure of disease and the achievement of positive health, covering all necessary domiciliary and institutional care, medical and postmedical.

The family should be the unit of health practice; and the family practitioner must be the focal point of all health services-preventive, educational and curative. Practice must be limited so that it affords adequate rest, leisure and holidays and all opportunities for 'refresher courses', and should be so rewarded that freedom from want for the practitioner and his dependants is secured. The profession should be self-governed and independent of political pressure, and the fullest opportunities should be provided for medical education and research. These general propositions should be assured of much support outside the medical profession. Prof. Cohen also emphasizes the importance of regionalism: the State is too large a unit in medical services, and the local authority too small. What he has to say of teaching hospitals is of close interest to scientific workers other than those who are actually members of the medical profession, and he directs attention to the opportunity of determining the eventual form of the health service of Great Britain which the demobilization of thousands of younger medical men at the end of the War may well afford, by experimenting with different types of health services in different areas.

\section{Biology and Health Education}

THE importance of biological teaching in the schools as a basis for health education was stressed at a conference held in the City Museum, Leeds, on April 17. This, the first of a series being arranged throughout Great Britain by the Central Council for Health Education, was attended by some three hundred teachers, medical practitioners, youth leaders, social workers and educational and medical ad. ministrators. This fruitful co-operation between the two professions most concerned in health education was signalized by Dr. J. Johnstone Jervis (medical officer of health for Leeds) taking the chair during the morning session and by Alderman W. M. Hyman (chairman, West Riding Education Committee) during the afternoon session.

Dr. Robert Sutherland (medical adviser, Central Council for Health Education), speaking on "The Possibilities of Health Education", stressed the importance of the concept of health as a positive state of bounding well-being, rather than as a mere absence of disease. The address on "Health Habits and Hazards" given by Dr. J. F. Galloway (medical officer of health, Dewsbury) made the point that the greatest hope for the health of the future is in the schools. At the afternoon session, Mr. Cyril Bibby (education officer, Central Council) spoke on "The Methods of Health Education", and suggested ways in which parents, teachers, administrators, youth leaders, school doctors, dentists and nurses, health visitors, and by no means least, 'John and Jane Citizen', could co-operate. An open forum provided a very fruitful exchange of views between the various professions represented, and the conference closed with a display of health education films. 